\title{
Does an orthotic treatment help the outcome of the spinal fusion in idiopathic scoliosis?
}

\author{
Alin B Circo*, Christine Coillard, Charles-Hilaire Rivard \\ From 7th International Conference on Conservative Management of Spinal Deformities \\ Montreal, Canada. 20-22 May 2010
}

\section{Introduction}

The purpose of this retrospective study was to evaluate the post surgical stability of the spine in patients suffering for idiopathic scoliosis and treated with the Dynamic SpineCor brace. Does the brace treatment alter in any way the post surgical results?

\section{Material and methods}

All the patients included in this study where operated by the same surgeon, between 2002 and 2006 at the Ste-Justine hospital, Montréal, using the same technique and the same instrumentation. 61 patients aged 11 to 17 years (mean 14,061 ) where included in the study. Out of the 61 patients, 34 had no previous treatment and 27 where previously treated with the SpineCor orthosis. All the patients had at least 2 years of follow-up. The evaluation was done by comparing the percentage of correction of their Cobb angle before, immediate after and at least at 2 years after the surgery.

\section{Results}

Regarding the 27 patients with a previously treated with the SpineCor brace, they had a mean pre surgery Cobb angle of $65^{\circ}$ and a mean Risser sign of 0.62 compared with the control group (34 patients with no previous treatment) with a mean pre surgery Cobb angle of $60.5^{\circ}$ with a mean Risser sign of 2.08. The mean post surgery Cobb $18.4^{\circ}$ for the treated group and $14.7^{\circ}$ for the control group and at 2 years of follow up $20.4^{\circ}$ and $16.6^{\circ}$ respectively.

\section{Discussion}

Even though there is a difference in the moment of the surgery between the two groups (the patients in the control group where more mature: Risser sign of 2.08 vs 0.62 ), the post surgery results are not statistically different. It seems that intra-operative the patients that whore

Sainte-Justine Hospital, Montreal, Canada

Full list of author information is available at the end of the article the SpineCor brace had a more flexible spine, although with or without the brace treatment the post surgery Cobb angle is reduced to almost $25 \%$ and that the progression 2 years after the surgery is of another $9 \%$. A new study needs to be done in order to measure and compare the flexibility of the spine. A good paring of patients and a torque measurement are necessarily as well as a follow-up regarding the quality of life.

\section{Conclusion}

In conclusion, this preliminary study did not show a statistical difference in the outcome of the spinal fusion in patients that had a bracing treatment recommended before the surgery versus the patients with no previous treatment. A new study needs to be done in order to measure and compare the flexibility of the spine.

Published: 10 September 2010

doi:10.1186/1748-7161-5-S1-054

Cite this article as: Circo et al:: Does an orthotic treatment help the outcome of the spinal fusion in idiopathic scoliosis?. Scoliosis 2010 5(Suppl 1):054.

Submit your next manuscript to BioMed Central and take full advantage of:

- Convenient online submission

- Thorough peer review

- No space constraints or color figure charges

- Immediate publication on acceptance

- Inclusion in PubMed, CAS, Scopus and Google Scholar

- Research which is freely available for redistribution 